\title{
Design and Evaluation of a Concentrated Solar-Powered Thermal- Pasteurization System
}

\author{
B.D. Plourde ${ }^{1}$, A. Gikling ${ }^{1}$, T. Marsh ${ }^{1}$, M.A. Riemenschneider ${ }^{1}$, J.L. Fitzgerald ${ }^{1}$, W.J. \\ Minkowycz ${ }^{2}$, J. Kiplagat ${ }^{3}$ and J.P. Abraham ${ }^{1, *}$ \\ ${ }^{1}$ University of St. Thomas, School of Engineering, 2115 Summit Ave, St. Paul, MN 55105-1079 \\ ${ }^{2}$ University of Illinois, Chicago, Department of Mechanical and Industrial Engineering, 2039 Engineering \\ Research Facility, 842 W. Taylor St. Chicago, IL 60607 \\ ${ }^{3}$ Kenyatta University, PO Box 438440-00100, Nairobi, Kenya
}

\begin{abstract}
A device has been designed, constructed, and tested for heating fluids using solar energy. The device heats water to levels to kill pathogens by a parabolic reflecting surface that concentrates solar energy along an axis. Among the components that increase the thermal performance of the system is a thermally actuated valve, which controls the temperature and the thermal exposure duration of the fluid to cause deactivation of targeted pathogens. Also, a novel fluid-to-fluid heat exchanger arranged in counter flow is used.

Experiments were performed with a water solution containing non-pathogenic Escherichia coli K-12 MG1655 (E. coli) bacteria. The results showed that the system is capable of pasteurization to levels where no living pathogens were detected in the heated fluid. The experiments were carried out over a wide range of temperatures and exposure durations to test the device and the underlying mathematical model. E. coli log reductions greater than 1 were achieved in all cases and it is shown that arbitrary values of reduction can be achieved with appropriate temperature/time settings.
\end{abstract}

Keywords: Thermal pasteurization, Solar concentration, Clean water, Renewable energy, Water quality.

\section{INTRODUCTION}

Human illness caused by water-borne pathogens is a major global health risk in the developing world. It also causes illness in certain areas and situations in the developed world, particularly after natural events destroy industrial-scale water treatment facilities.

Currently, hundreds of millions of people do not have regular access to potable water and face the consequent risk of illness [1-4]. There are nearly 30 billion incidents of diarrhea each year worldwide. For at-risk populations, particularly children, unclean water is a major cause of diarrhea [5]. The ability to turn unclean water potable would provide very large humanhealth benefits and reduce the social and economic costs associated with unclean water.

There are many methods to treat water-borne pathogens including filtering [6-7] chemical treatment, ultraviolet light [8-9], reverse osmosis, and thermal pasteurization [2-3, 10-13]. Each treatment technique has certain advantages and disadvantages that make its use more appropriate in a specific situation. Here, thermal pasteurization is the chosen treatment method. First, this method does not require the expensive

*Address correspondence to this author at the University of St. Thomas, School of Engineering, 2115 Summit Ave, St. Paul, MN 55105-1079;

Tel: 612-963-269; E-mail: jpabraham@stthomas.edu equipment, chemicals, and expertise as does chemical treatment. It is not susceptible to light-blocking particulates (such as in UV treatment). It can have a high output, and does not require expensive and frequent filter changes. Thermal pasteurization does not remove particulates within the fluid, rather it destroys the living organisms so that they cannot cause infection.

It is well known that pathogens, when subjected to elevated temperatures, will be killed. A large body of literature is available which quantifies the temperaturetime requirement to cause deactivation of various pathogens. These data are not summarized here for brevity but readers are directed to a recent publication [14] for more information.

The purpose of this study is to test a water heating system that can reach temperatures typical of heating by concentrated solar radiation. In particular, the test is intended to assess the ability of a pathogen deactivation algorithm to predict $E$. coli survival rates during water-flow situations. The success of the algorithm is crucial for the deployment of a real-world device for water pasteurization in either the developed or developing world.

\section{DESCRIPTION OF THE PASTEURIZATION SYSTEM}

The thermal pasteurization system is shown schematically in Figure 1. As seen in the figure, water 


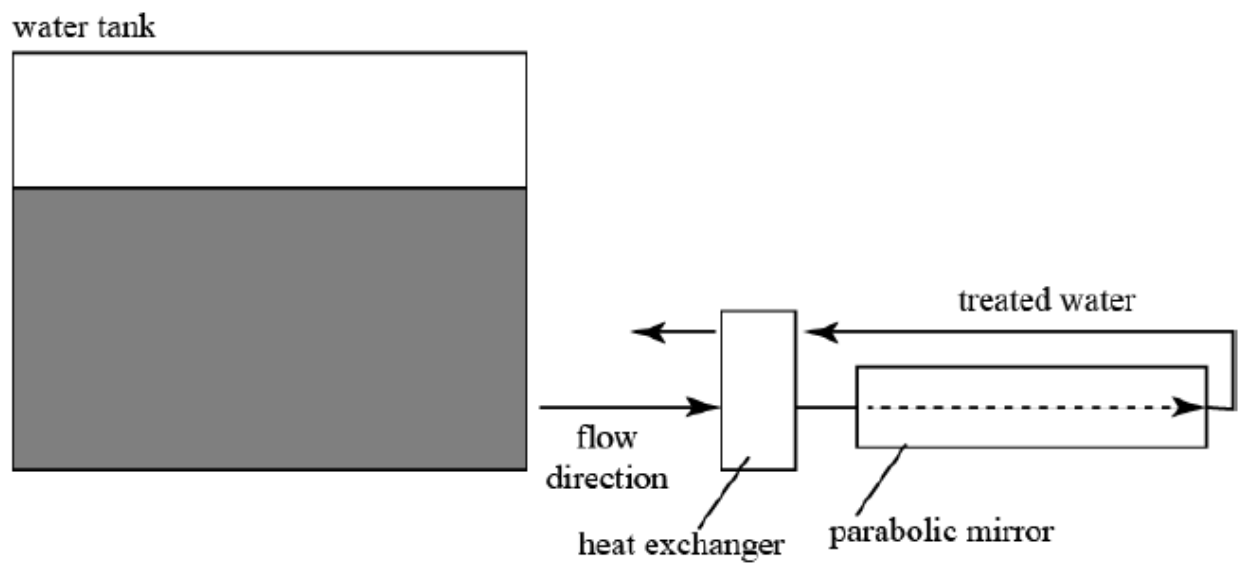

Figure 1: Schematic diagram of a parabolic trough pasteurization system (not to scale). Image reproduced from [14].

travels from an external supply; in the schematic, the supply is a tank. However, it could be a pressurized source of water, from a well, or even surface water. Water passes through a heat exchanger prior to entering the thermal pasteurization system. The purpose of the heat exchanger is to preheat the incoming fluid by extracting thermal energy from the already heated water - in this way, thermal efficiency is increased. Following the heat exchanger, the water travels along the focal length of a parabolic mirror. After passing through the mirrored region, flow direction is reversed and the water makes a second traverse. Finally, the heated water is cooled by the already mentioned heat exchanger and then leaves the system.

The general range of operation was $70-80{ }^{\circ} \mathrm{C}$ for durations of approximately 1 minute. This operating range was chosen for a number of reasons. Certainly, the incoming solar energy can allow water to reach temperatures much in excess of this range. On the other hand, the goal of this device is to maximum potable water production in a safe and effective manner. Using temperatures in excess of $80^{\circ} \mathrm{C}$ results in greater heat loss to the environment and exposed surface temperatures, which are sufficiently hot to cause injury. Furthermore, heating above $80{ }^{\circ} \mathrm{C}$ is not necessary for deactivating pathogens such as $E$. coli. At the same time, temperatures below $\sim 70{ }^{\circ} \mathrm{C}$ require too much time to reach thermal deactivation and consequently; the system loses efficiency and flow rate capacity.

A more descriptive image of the system is provided in Figure 2. The figure is annotated to call out components of the system. Of note in the figure is the heat exchanger on the right-hand side and a structure on the left-hand side which is used to reverse the fluid direction, measure temperature and pressure, and employ valves which permit flow only when a prescribed temperature and exposure duration is achieved.

Figure 3 has been prepared to display details of the structure which contains the thermally actuated valves and the temperature measurement device (thermistor).

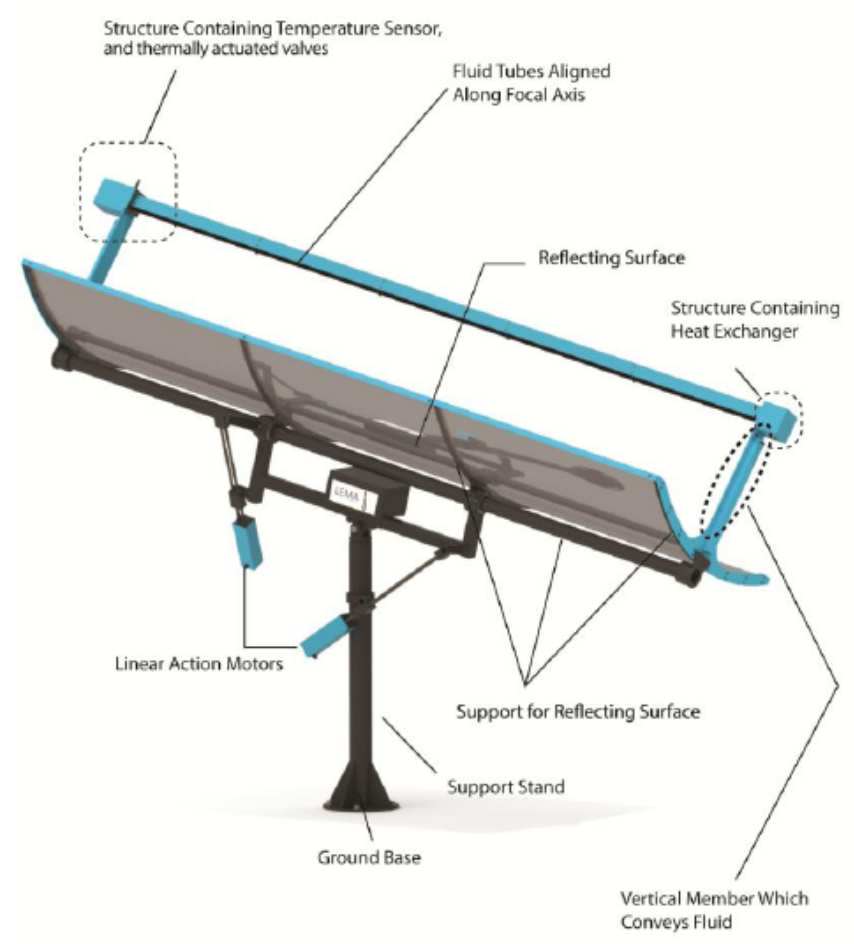

Figure 2: Thermal pasteurization device, components annotated.

Next, Figure 4 has been prepared to illustrate the passage of fluid through the system. Untreated water enters at the lower right-hand side of the image, passes along the focal axis, reverses direction, and then leaves through the lower right-hand side. 


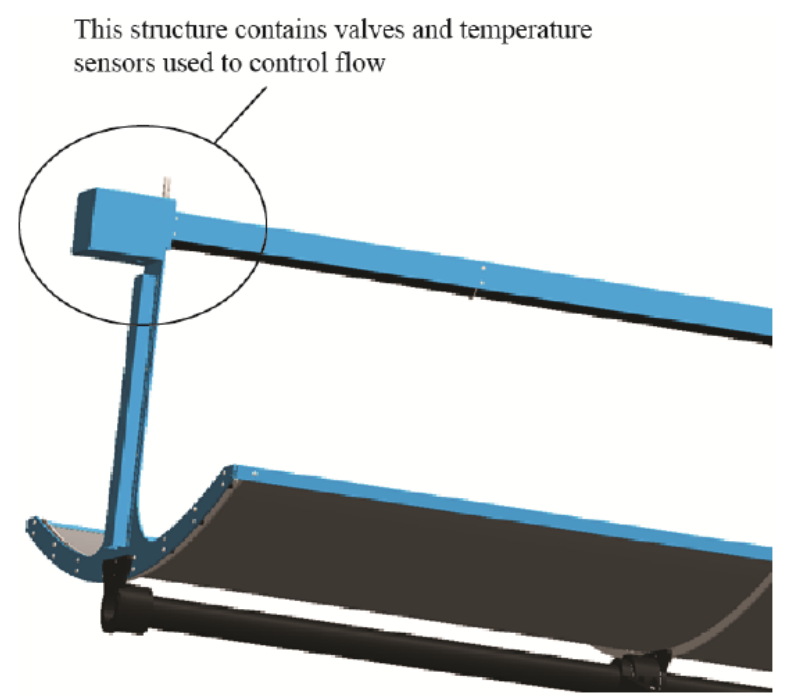

Figure 3: Position of structure that houses temperature sensors and flow-control valves.

While not the subject of this study, a brief discussion of the structure will be provided as background information. The reflecting surface is held in position and shape by a series of ribs which can be seen in Figures $\mathbf{2}$ and $\mathbf{4}$. Two linear motors are used to orient the system toward the sun. The system can be connected to photovoltaic panels to extend the lifetime of the batteries which provide electrical power to the motors. The system includes global positioning software to facilitate solar tracking, although even without auxiliary power, the battery lifetime exceeds a month.

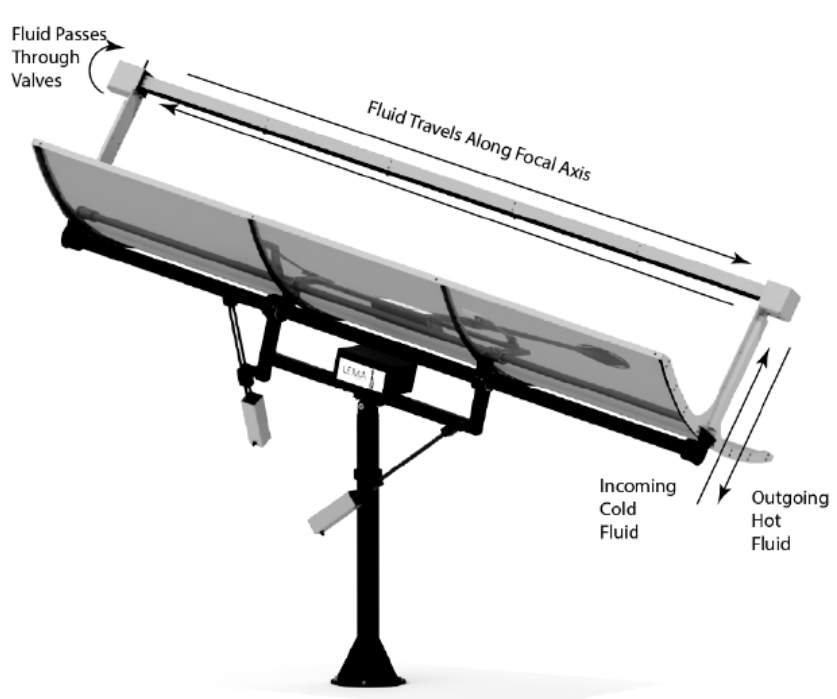

Figure 4: Flow path through the thermal pasteurization system.

The use of tracking is not essential in a solarthermal system such as that discussed here. However, there are certain reasons why this technology was implemented. First, a high-efficiency tracking algorithm was developed that allowed low cost motors to be used. These motors, with the efficient tracking algorithm use very little energy [15]. Secondly, the tracking significantly increases water production during morning and early evening hours, when demand is high. A non-tracking device is unable to gather sufficient solar energy during these times because of the low incidence angle of sunlight. A third reason is that the device is intended for use in a wide variety of climates, some of which will require tracking (high northern latitudes for instance). Rather than constructing two types of devices (a non-tracking device for tropical regions and a tracking device for high latitudes), a single, universal device was designed and constructed.

\section{MATHEMATICAL MODEL}

The starting point for the numerical model is one that connects the temperature of fluid to the instantaneous change in pathogen concentration. In this regard, a first-order rate equation is used that relates the change in concentration to the instantaneous concentration $(N)$ of pathogens.

$$
\frac{d N}{d t}=-k N
$$

Here, $k$ is a rate constant that connects the reaction rate to the viable pathogen population. For situations where temperature changes in time, this can be numerically integrated as

$\frac{d N}{d t}=\frac{\left(N_{t+\Delta t}-N_{t}\right)}{\Delta t}=-k N_{t}$

The values of the rate constant $(k)$ are obtained through experiments. The experimental results are measurements of the time required for a log-reduction. This log reduction is typically put into the form

$$
\log \left(\frac{N_{t}}{N_{0}}\right)=\frac{-t}{D}
$$

In order to complete the analysis, the constants $k$ and $D$ must be related. Here, $N_{0}$ and $N_{t}$ are the populations of a pathogen at an initial time and at some later time, $t$. The symbol $D$ governs the rate of population decrease. A major complication is that $D$ is not constant with temperature, in fact, it quickly decreases as temperature increases according to 
$\log \left(\frac{D}{D_{r}}\right)=\frac{-\left(T-T_{r}\right)}{z}$

Here, $D_{r}$ is the value of $D$ at some reference temperature $T_{r}$. The symbol $z$ which describes the rate of change of $D$ with temperature has units of ${ }^{\circ} \mathrm{C}$. Values of $z$ are specific to particular pathogens. With $D_{r}, T_{r}$ and $z$ known for a given organism, Eq. (4) allows $D$ to be found at any other temperature.

Integration of Eq. (2) and comparison of the result with Eq. (4) leads to the following relationship between $k$ and $D$ :

$k=\frac{2.303}{D}$

so that Eq. (2) becomes

$\frac{d N}{d t}=\frac{\left(N_{t+\Delta t}-N_{t}\right)}{\Delta t}=-k N_{t}=\frac{2.303}{D_{r}} \cdot 10^{\frac{\left(T-T_{r}\right)}{z}} \cdot N_{t}$

It is this equation which will be used in a forwardmarching timewise integration for the calculation of $N(t)$ for all times and for any temperature exposure.

Equation (6) is solved until the desired concentration of surviving pathogens is achieved. Values of pathogen inactivation constants are available [16-17] however it should be noted that there is large spread in the reported data.

A detailed review of inactivation kinetics, heat transfer to the fluid, and flow determination is provided in [14] and is not repeated here. Prior work has set forth foundational analysis of parabolic systems such as that considered here [18-23] which, when combined with basic heat transfer analysis contained in [24-29] along with quantification of incident solar energy [30] provides the necessary information to calculate the rate of heat transfer to the working fluid. For brevity, that thermal analysis is not repeated here. Since the focus here is on the ability of an algorithm to predict pathogen inactivation in a flow-through system, the heating will be carefully controlled initially, in non-field conditions. Later the device will be deployed for in-field experiments.

\section{EXPERIMENTAL METHOD}

The device was found to quickly reach temperatures which would lead to thermal pasteurization through the use of solar power. However, in an effort to achieve long-time stability of temperatures for the present manuscript, auxiliary heaters were employed. The heaters are electrical resistance heaters that are flexible which allows them to be wound around the pipe. The thin electrical wires were wrapped with a polymeric protective coating for protection. Voltage current (and resistance) was measured so that the power dissipation could be determined.

It was decided to use the auxiliary heaters for two reasons. These heaters enable very stable temperatures to be maintained so that replicate experiments could be made. Stable temperatures facilitate testing the inactivation algorithm. Furthermore, the heaters allowed lower temperatures than is easily achievable using direct solar irradiation. For solar heating, temperatures within the water would quickly rise to near boiling making experiments in the $\sim 70{ }^{\circ} \mathrm{C}$ range challenging to perform.

At test initiation, experiments were preceded with elevated temperature flushing of the system with water temperatures of $\sim 95{ }^{\circ} \mathrm{C}$ in order to guarantee no residual viable bacteria. In addition, the system was regularly cleaned with a bleach solution to further guard against any possible bacteria growth. Then, E. coli spiked water at $\sim 15{ }^{\circ} \mathrm{C}$ was connected to the system and passed into the thermal processing device. The $E$. coli strain K-12 MG1655 was acquired from American Type Culture Collection (ATCC). The cultures were grown and maintained in Lysogeny at $37{ }^{\circ} \mathrm{C}$ to a late log phase cell density prior to introduction into the water reservoir. Water samples collected post pasteurization were filtered through sterile $45 \mathrm{~mm}$ diameter, $0.45 \mu \mathrm{m}$ pore membranes which were transferred onto sterile paper discs saturated with Lysogeny. The colonies were grown overnight and counted manually.

Temperatures were continually recorded using a National Institute of Standards and Technology (NIST) traceable thermistor which is positioned in the chamber in the upper left portion of Figures 2-4.

\section{RESULTS AND DISCUSSION}

An example of the output is shown in Figure 5. The figure shows two sets of data. One set corresponds to temperatures which were targeted by the system and the other data is from actual measurements. The experimental target temperatures are reached by a control algorithm that modulates the rate of water flow through the system. It is seen that there is very good agreement between the results, the time-average of the absolute value of temperature differences was less 


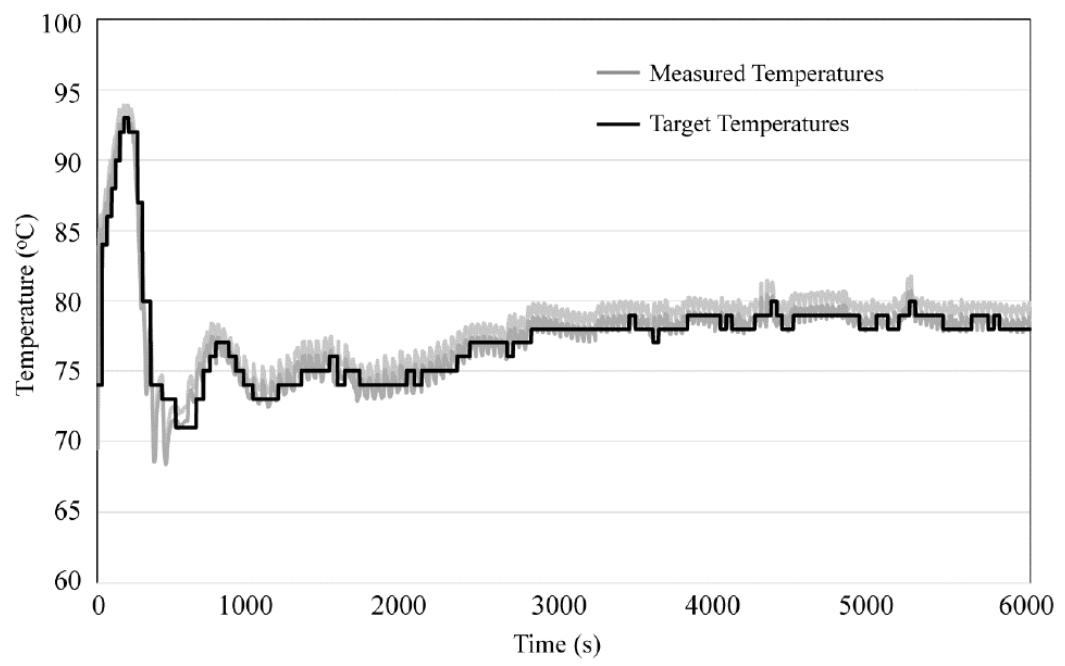

Figure 5: Comparison between measured and targeted temperatures within the system.

than $1{ }^{\circ} \mathrm{C}$. That means, on average, the target and actual temperatures were within $1{ }^{\circ} \mathrm{C}$. Furthermore, a linear regression of the predicted temperatures against the actual temperature measurements revealed an agreement with $\mathrm{R}^{2}=0.89$.

The measured temperatures are represented by two grey-colored curves that indicate the upper and lower bounds of the measurement. The accuracy is based on both the resolution of the instrument as well as uncertainties related to temperature sensor location within the device. The actual temperature measurements fluctuate rapidly as valves open and close to maintain isothermal conditions within the system however the fluctuations are confined to very narrow ranges near the targeted set point. Similarly, excellent agreement is obtained if no auxiliary heaters are used (only solar thermal heat) however those results are not shown for brevity. As mentioned earlier, when solar energy is used, the temperature rises are much faster than with auxiliary heaters and much higher temperatures are reached.

With the thermal stability of the system thus demonstrated, biological tests were carried out with the preloaded $E$. coli suspended in water solution. The bacterial solution was stored in a 65 -gallon (246 liters) tank and heavily stirred to ensure uniform distribution of bacteria.

For each experiment, measurements are made of the number of colony forming units (CFUs) before and after passing through the device. Multiple experiments were performed in replicate (repeated temperature and duration targets) and these replicate experiments were performed at various temperature/duration combinations. Table 1 provides a summary of the temperature and exposure duration for the experiments. Also listed in the table is the \% reduction of viable $E$. coli and the corresponding log reduction.

Table 1: Summary of E. Coli Reduction for Various Heating Scenarios

\begin{tabular}{|c|c|c|c|c|}
\hline Data set & $\mathbf{T}_{\text {setpoint }}(\mathbf{C})$ & $\mathbf{t}_{\text {exposure }}(\mathbf{s e c o n d s})$ & Measured \% reduction & Measured log reduction \\
\hline \hline 1 & 71 & 41.1 & 90.5 & 1.02 \\
\hline 2 & 73 & 26.7 & 93.0 & 1.15 \\
\hline 3 & 74 & 21.5 & 92.0 & 1.10 \\
\hline 4 & 75 & 17.2 & 94.3 & 1.25 \\
\hline 5 & 76 & 13.9 & 96.8 & 1.49 \\
\hline 6 & 77 & 11.2 & 96.8 & 1.49 \\
\hline 7 & 78 & 9.0 & 94.3 & 1.24 \\
\hline 8 & 79 & 7.3 & 96.4 & 1.44 \\
\hline
\end{tabular}


Next, predictions of the pathogen destruction are presented, attained from numerical integration of Eq. (6). That equation, with $D_{r}$ and $Z$ values of 18 and 8.7 seconds, respectively, was used for the cases listed in Table 1. Those predicted pathogen reduction results are shown in Table 2. It is seen that there is excellent agreement between the predicted and measured results - supporting the use of the predictive model as a means for setting the thermal actuation protocols in order to achieve a desired pasteurization level.

A graphical comparison between the predictions and the experiments is provided in Figure 6 . This close agreement provides confidence in the predicted values.

With the aforementioned $D_{r}$ and $Z$ values, it is possible to provide a continuous relationship between fluid temperature within the system and required duration in order to achieve any arbitrary E. coli reduction target. For instance, Figure 7 shows the unique temperature/time relationship required for a 3log reduction in $E$. coli bacteria within the device. Similar graphical results could be provided for other pathogenic strains.

The final stage in the study was the evaluation of the device in field. During the in-field tests, all heating was supplied by solar energy, the experiments were performed on October 22, 2016 in western Wisconsin, USA (coordinates $45^{\circ} 8^{\prime} 30^{\prime \prime} \mathrm{N}, 92^{\circ} 42^{\prime} 9^{\prime \prime} \mathrm{W}$ ). During the experiments, the ambient temperature was approximately $10^{\circ} \mathrm{C}\left(50^{\circ} \mathrm{F}\right)$ (varied slightly throughout the day), a mostly sunny sky, and a light breeze. The latitude of the test location, time of year, and low daytime air temperatures provided a challenging environment for thermal performance.

The device was loaded with an E. coli solution as input. During the day, 88 liters of treated water were produced. Nearly 120 separate experiments were

Table 2: Predicted E. Coli Reduction Corresponding to Experiments of Table 1

\begin{tabular}{|c|c|c|c|c|}
\hline Data Set & $\mathbf{T}_{\text {setpoint }}(\mathbf{C})$ & $\mathbf{t}_{\text {exposure }}$ (Seconds) & Predicted \% Reduction & Predicted Log Reduction \\
\hline \hline 1 & 71 & 41.1 & 90.7 & 1.03 \\
\hline 2 & 73 & 26.7 & 92.7 & 1.14 \\
\hline 3 & 74 & 21.5 & 94.3 & 1.19 \\
\hline 4 & 75 & 17.2 & 95.1 & 1.25 \\
\hline 5 & 76 & 13.9 & 95.8 & 1.31 \\
\hline 6 & 77 & 11.2 & 96.4 & 1.44 \\
\hline 7 & 78 & 9.0 & 96.9 & 1.51 \\
\hline
\end{tabular}

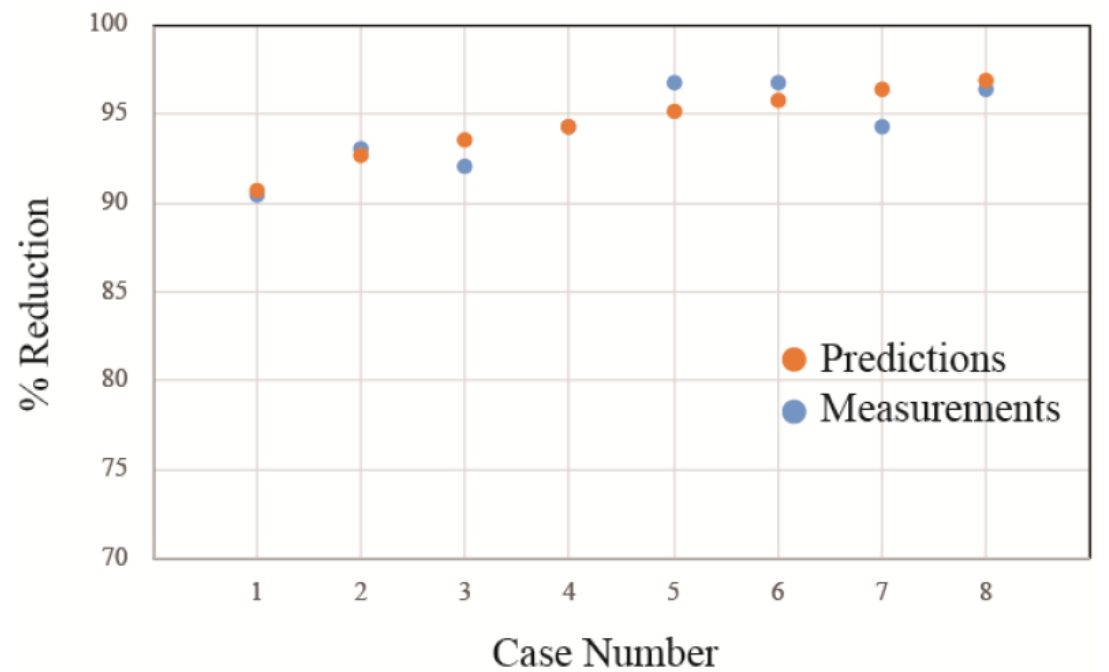

Figure 6: Comparison of measured and predicted $E$. coli reductions corresponding to cases listed in Tables 1 and 2. 


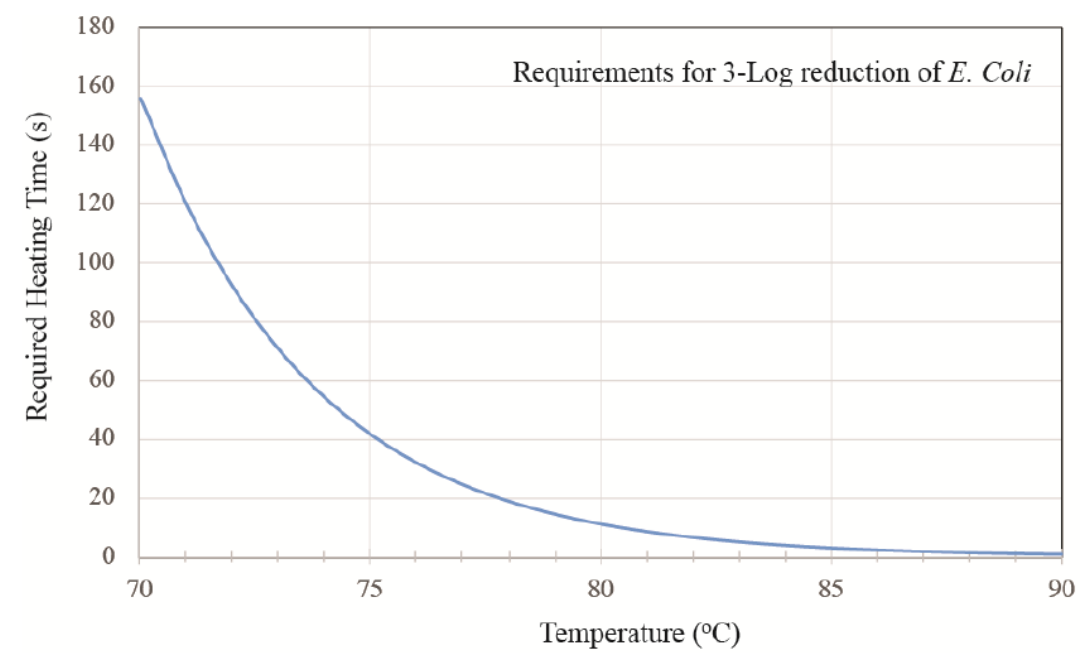

Figure 7: Temperature and exposure durations which produce a 3-log reduction in $E$. coli concentrations for the fluid heating device.

performed and the concentration of $E$. coli after treatment were measured. It was found that the average E. coli reduction was $95 \%$. This level of reduction, attained in a cool ambient in the northern hemisphere with low-altitude incident solar radiation strongly reinforces the thermal performance and potential capacity of the device in a warmer location with more direct sunlight.

An important part of assessment of this water pasteurization product is based on economic viability. Included here is not only the cost to manufacture, transport, and erect a device but also maintenance cost and comparisons with other water-treatment options.

Early stage manufacturing suggests that the cost of manufacturing the product in large quantities will be approximately 2,500 US dollars. While transportation costs vary depending on the distance and accessibility of the installation location, a conservative value of 500 USD is used as the current estimate (based on recent field deployments). The device is designed to be robust and survive in harsh environments with minimal human interaction. Monitoring can be performed remotely and sensors are used to detect faults within the system. Consequently, operational costs are low.

Currently, lifetime tests are underway however those results are not yet available. By design, the fluid heating system is intended to have a lifetime of 15 years. In warm environments (particularly locations where cloud cover is low), an average production rate of 450 liters (120 gallons) per day are expected. The total heating power delivered to the water is approximately 3900 Watts, over approximately 8 hours a day. Over the expected lifetime of the device, it is anticipated that 1.9 million liters ( 0.5 million gallons) are produced in an area with an average of 275 sunny days per year. With a competitively priced 0.10 USD for each treated liter, the payback is approximately 4 months. This value compares very favorably to other treatments such as chemical, boiling with fuel, or filtering. A cheap alternative to these is the use of charcoal for boiling. Charcoal, however, leads to deforestation, indoor air quality issues, and is very time consuming for the end user of the water.

\section{CONCLUSION}

In this study, a new solar-pasteurization system has been designed, built, and tested. It operates through thermal deactivation of pathogens caused by concentrated solar heating to fluid flowing through a pipe that is aligned along the focal axis of the reflecting surfaces.

The system is fully automated through wireless communication to a handled GPS device or a smartphone. The positioning enables the system to automatically track to sun throughout the day, increasing thermal efficiency.

Contaminated water flows from an external source such as elevated storage tank, surface water source, contaminated well, or others. The unheated water flows into the system where it encounters a heat exchanger, flow piping, and an enclosure with a thermally controlled valve, pressure sensor, and temperature sensors. Piping is arranged in a counter flow configuration to improve thermal efficiency. 
Experiments were carried out with many temperature/duration combinations with various $E$. coli destruction targets. In the experiments, carefully prepared E. coli loads were suspended in water. The concentration of colony forming units were measured prior to the experiments. Next the water was heated according to the specific thermal protocol and the concentration of viable pathogens was again measured. In all experiments, E. coli (K-12 strain MG $1655)$ bacteria were used as the model $E$. coli.

Then, measurements were made of the temperature within the fluid system to demonstrate that the numerical algorithm that controlled the thermally actuated valves was able to properly function and that the actual fluid temperatures in the system were a very close match with the targeted temperatures.

Next, predictions for each thermal protocol were made and these predictions were compared with the measured values (Tables $\mathbf{1}$ and $\mathbf{2}$ and Figure $\mathbf{6}$ ). It was found that in all cases, there was a large reduction in the concentration of active $E$. coli and the predictions agreed very well with the measurements. While the entire study was confined to $E$. coli bacteria, it can be extended to other bacteria, viruses, protozoa, or worms with a simple modification of the cell-kill parameters.

Finally, 120 in-field tests were carried out on October 22, 2016 in a northern latitude location. Despite the date of the test, location, and air temperature, the device was found to be effective at treating $E$. coli laden water. The production rate was 88 liters per day and the $E$. coli reduction was well over $90 \%$. In warmer climates or at other times of the year (boreal summer for instance), the device is expected to produce an average of approximately 450 liters per day with a payback of less than 1 year (approximately 4 months). The temperatures treated during these experiments varied with time but were almost always $\sim 80^{\circ} \mathrm{C}$. These temperatures are similar to those shown here.

\section{REFERENCES}

[1] World Health Organization, Progress on Drinking Water and Sanitation, Joint Monitoring Programme Update 2012, World Health Organization: UNICEF, (2012).

[2] JD. Burch and KE. Thomas, An overview of water disinfection in developing countries and the potential for solar thermal water pasteurization, National Renewable Energy Laboratory, NREL/TP-550-23110, (1998).

[3] JD. Burch and K.E. Thomas, Water disinfection for developing countries and potential for solar thermal pasteurization, Solar Energy, 1998; 64: 87-97. https://doi.org/10.1016/S0038-092X(98)00036-X
[4] L. Liu, HL. Johnson, S. Cousens, et al., Child health epidemiology reference group of WHO and UNICEF, Lancet, 2012; 379: 2151-2161. https://doi.org/10.1016/S0140-6736(12)60560-1

[5] A. Gadgil, Drinking water in developing countries, Annual Reviews of Energy and the Environment, 1998; 23: 253-286. https://doi.org/10.1146/annurev.energy.23.1.253

[6] R. Feachem, DJ. Bradley, and DD. Mara, Sanitation and disease: Health aspects of excreta and wastewater management, John Wiley and Sons, New York, NY (1983).

[7] L. Huisman and WE. Wood, Slow sand filtration, World Health Organization, Geneva, (1974).

[8] C. Svrek and DW. Smith, Cyanobacteria toxins and the current state of knowledge on water treatment options: a review, Journal of Environmental Engineering and Science, 2004; 3: 155-185. https://doi.org/10.1139/s04-010

[9] JL. Zimmer and RM. Slawson, Potential repair of Escherichia coli DNA following exposure to UV radiation from both medium- and low-pressure UV sources used in drinking water treatment, Applied Environmental Microbiology, 2002; 68: 3293-3299.

https://doi.org/10.1128/AEM.68.7.3293-3299.2002

[10] DC. Walker, SV. Len, and B. Sheehan, Development and evaluation of a reflective solar disinfection pouch for treatment of drinking water, Applied Environmental Microbiology, 2004; 70: 2545-2550.

https://doi.org/10.1128/AEM.70.4.2545-2550.2004

[11] DA. Ciochetti and RH. Metcalf, Pasteurization of naturally contaminated water with solar energy, Applied Environmental Microbiology, 1984; 47: 223-228.

[12] TS. Saitoh and HH. El-Ghetany, Solar water-sterilization system with thermally controlled flow, Applied Energy, 1999; 64: 387-399.

https://doi.org/10.1016/S0306-2619(99)00086-0

[13] LF. Caslake, et al., Disinfection of contaminated water by using solar irradiation, Applied and Environmental Microbiology 2004; 70: 1145-1150.

https://doi.org/10.1128/AEM.70.2.1145-1150.2004

[14] BD. Plourde, J.P.Abraham, and W.J. Minkowycz, Continuous flow solar thermal pasteurization of drinking water: Methods, devices, microbiology, and analysis, Renewable Energy, 2015; 81: 795-803.

https://doi.org/10.1016/j.renene.2015.03.086

[15] BD. Plourde, JP. Abraham, DR. Plourde, A. Gikling, and R. Pakonen, 2018, Dual-Axis Tracking Device, U.S. Patent \# 10168412 (2018).

[16] AT. Spinks, RH. Dunstan, T. Harrison, P. Coombes, and G. Kuczera, Thermal inactivation of water-borne pathogenic and indicator bacteria at sub-boiling temperatures, Water Research, 2006; 40: 1326-1332.

\section{https://doi.org/10.1016/j.watres.2006.01.032}

[17] US. Food and Drug Administration, Kinetics of microbial inactivation for alternative for processing technologies overarching principles: Kinetics and pathogens of concern for all technologies http://www.fda.gov/Food/FoodScienceResearch/SafePractice sforFoodProcesses/ucm100198.htm

[18] GK. Rijal and RS. Fujioka, Synergistic effect of solar radiation and solar heating to disinfect drinking water sources, Water Science and Technology, 2001; 43: 155-162. https://doi.org/10.2166/wst.2001.0728

[19] WS. Duff and DA. Hodgson, A simple high efficiency solar water purification system, Solar Energy, 2005; 79: 25-32. https://doi.org/10.1016/j.solener.2004.10.005

[20] AM. Abdel Dayem, HH El-Ghetany, GE. El-Taweet, and MM Kamel, Thermal performance and biological evaluation of solar water disinfection systems using parabolic trough collectors, Desalination and Water Treatment, 2011; 36:119- 
128.

https://doi.org/10.5004/dwt.2011.2227

[21] N. Safapour and R.H. Metcalf, Enhancement of solar water pasteurization with reflectors, Applied and Environmental Microbiology, 1999; 65: 859-861.

[22] N. Fraidenraich, C. Tiba, BB. Brandao, and OB. Vilela, Analytic solutions for the geometric and optical properties of stationary compound parabolic concentrators with fully inverted V receiver, Solar Energy, 2008; 82: 132-143. https://doi.org/10.1016/j.solener.2007.06.012

[23] T. Tao, Z. Hongfei, H. Kaiyan, and A. Mayere, 2011 A new trough solar concentrator and its performance analysis, Solar Energy, 2011; 85: 198-207.

https://doi.org/10.1016/j.solener.2010.08.017

[24] TL. Bergman, A. Lavine, FP. Incropera, and DP. DeWitt, Introduction to Heat and Mass Transfer, $6^{\text {th }}$ edition, John Wiley and Sons, New Jersey (2011).

[25] EM. Sparrow, JP. Abraham, and JCK. Tong, Archival correlations for average heat transfer coefficients for noncircular and circular cylinders and for spheres in crossflow, International Journal of Heat and Mass Transfer, 2004; 47: 5285-5296.

https://doi.org/10.1016/j.ijheatmasstransfer.2004.06.024
[26] AV. Hollands and K.G.T Hassani, On natural convection heat transfer from three-dimensional bodies of arbitrary shape, Journal of Heat Transfer, 1989; 111: 363-371. https://doi.org/10.1115/1.3250686

[27] JP. Abraham and EM. Sparrow, Three dimensional laminar and turbulent natural convection in a continuously/discretely wall-heated enclosure containing a thermal load, Numerical Heat Transfer A, 2003; 44: 105-125. https://doi.org/10.1080/713838194

[28] JM. Gorman, E.M. Sparrow, and J.P. Abraham, Differences between measured pipe wall surface temperatures and internal fluid temperatures, Case Studies in Thermal Engineering, 2013; 1: 13-16. https://doi.org/10.1016/j.csite.2013.08.002

[29] JCK. Tong, JP. Abraham, JMY. Tse, WJ. Minkowycz, and EM. Sparrow, New archive of heat transfer coefficients from square and chamfered cylinders in crossflow, International Journal of Thermal Sciences, 2016; 105: 218-223. https://doi.org/10.1016/j.ijthermalsci.2016.03.008

[30] M. Li, Y. Jiang and CFM. Coimbra, on the determination of atmospheric longwave irradiance under all-sky conditions, Solar Engineering, 2017; 144: 40-48. https://doi.org/10.1016/j.solener.2017.01.006

Received on 13-3-2019

DOI: http://dx.doi.org/10.31875/2410-2199.2019.06.4

(C) 2019 Plourde et al.; Zeal Press.

This is an open access article licensed under the terms of the Creative Commons Attribution Non-Commercial License (http://creativecommons.org/licenses/by-nc/3.0/), which permits unrestricted, non-commercial use, distribution and reproduction in any medium, provided the work is properly cited. 